\title{
USEFUL APPLIANCE (PYLON) FOR BELOW-KNEE AMPUTATIONS
}

\author{
By Dean P. Currier, M.A., RPT \\ Chief, Physical Therapy Department, USPHS Hospital, \\ Carville, Louisiana
}

Where the services of a limb maker and monies are not immediately and readily available for the construction of complex and expensive appliances, resort is made to other devices. The pylon is such a device that meets most requirements for successful walking.

As soon as the stump can bear pressure the pylon consisting of a moulded plaster shell (socket), a shank and cuff suspension is constructed (Fig. 1). The pylon can be constructed within a hospital's facilities and with inexpensive available materials. Basic materials required are plaster, wood, leather and four metal strips (aluminium or stainless steel). Other materials include stockinette, wood screws, rubber and a few carpenter's tools such as a level, screwdriver, saw and pliers.

This pylon is light, durable and has no joints. It provides efficient function and wearing comfort to the amputee. Pylons are usually intended for temporary use to shorten the period of inactivity while waiting to be fitted with permanent appliances; however, it could be used as a permanent appliance. This device has been employed at the United States Public Health Service Hospital, Carville, Louisiana, as a temporary measure while waiting for completion of permanent prostheses. The skills learned while using the pylon are valuable and useful for any subsequent prosthesis. During its use the amputee adjusts to weight-bearing on the stump, learns to balance and walk in parallel bars. The pylon's use enables the gait training programme to start sooner by eliminating unnecessary waiting, thus proving to be a psychological boost to the amputee.

The amputee's ambulation time should be gradually increased within tolerance to practical limits. Starting with 10 minutes, ambulation time should be graduated so the amputee can wear the pylon during entire days' activities.

During the early stages of the pylon's use, one must watch for pressure signs. If pressure signs are present, the socket is readily sanded in appropriate areas to relieve excessive pressure points. If stockinette of double thickness is used and plaster is applied properly, pressure signs will be few, if any.

Few critical measurements are necessary for successful completion of the pylon. The over-all length and joint level measurements are taken to correspond with the normal leg. 


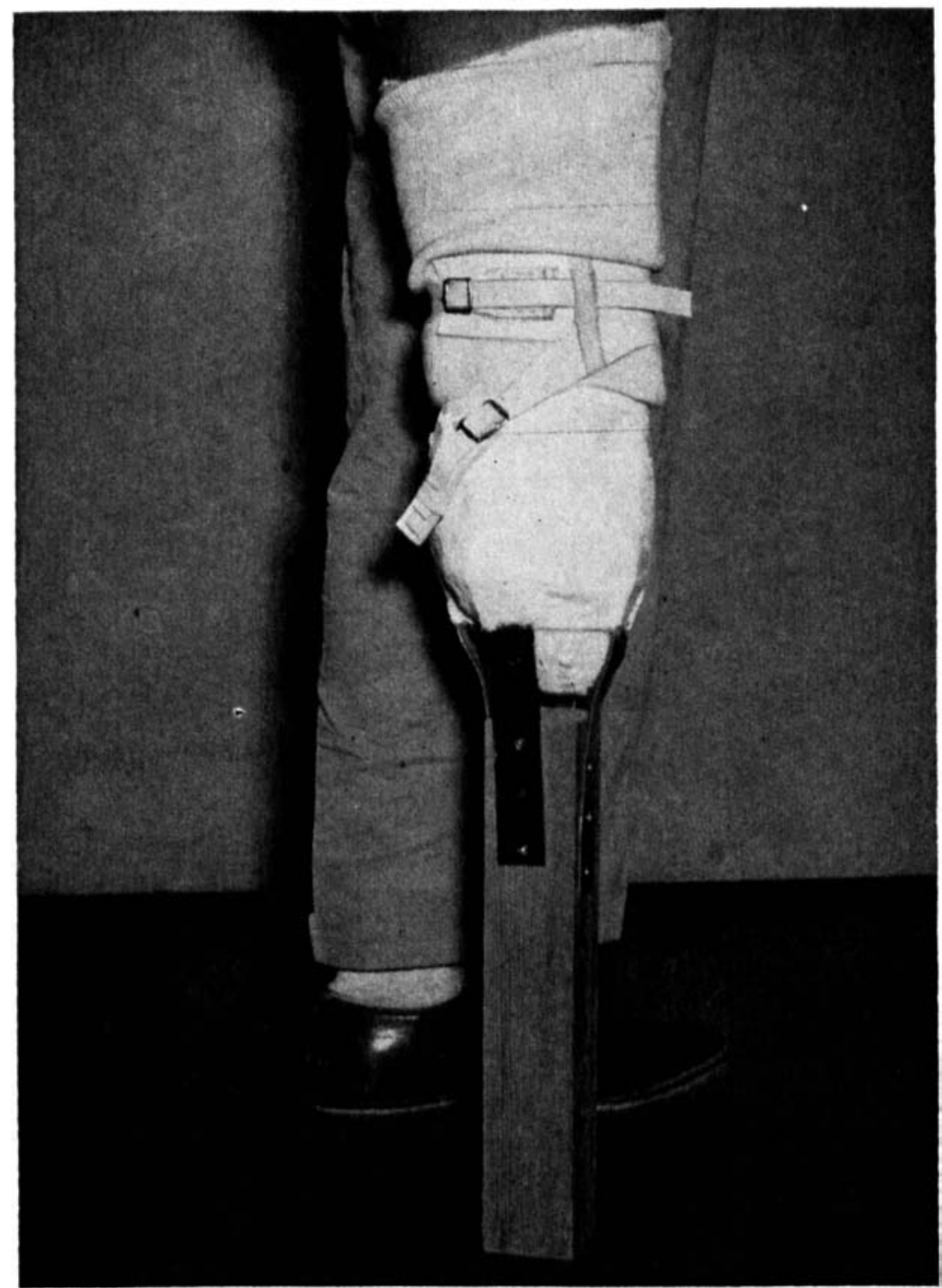

FIG 1. Useful appliance (pylon) for below-knee amputations.

The amputee is placed in a sitting position on a table with knee of leg to be fitted several inches or cms. beyond table's edge, and flexed to 25 degrees. This position emphasizes identification of bony prominences, the patellar tendon and hamstring tendons, thus ensuring reduced pressure to popliteal area and avoiding interference with knee flexion. ${ }^{1}$

Stockinette of double thickness and stitched at one end is placed over stump, knee and lower thigh to form a stump sock. The stockinette should be free from wrinkles which cause undesirable roughness in socket's interior. 
One-one half rolls of plaster-impregnated bandage gauze (or plaster-impregnated stockinette) are applied in a series of circumferential wraps. The plaster is smoothed and worked around bony prominences with each wrap. The proximal portion of the socket should not be higher than the tibial plateau or distal portion of the patella, while the distal portion of the socket should allow the stump end to be exposed and non-weight-bearing. The patellar tendon and medial and lateral flares of the tibial condyles are good weightbearing areas. As the plaster hardens, the thumb tips are pressed inwardly on both sides of the patellar tendon causing indentations while the fingers compress the popliteal tissues. The finger impressions made in the popliteal area serve to push the patellar tendon against the shelf (indentations) formed by the thumb tips.

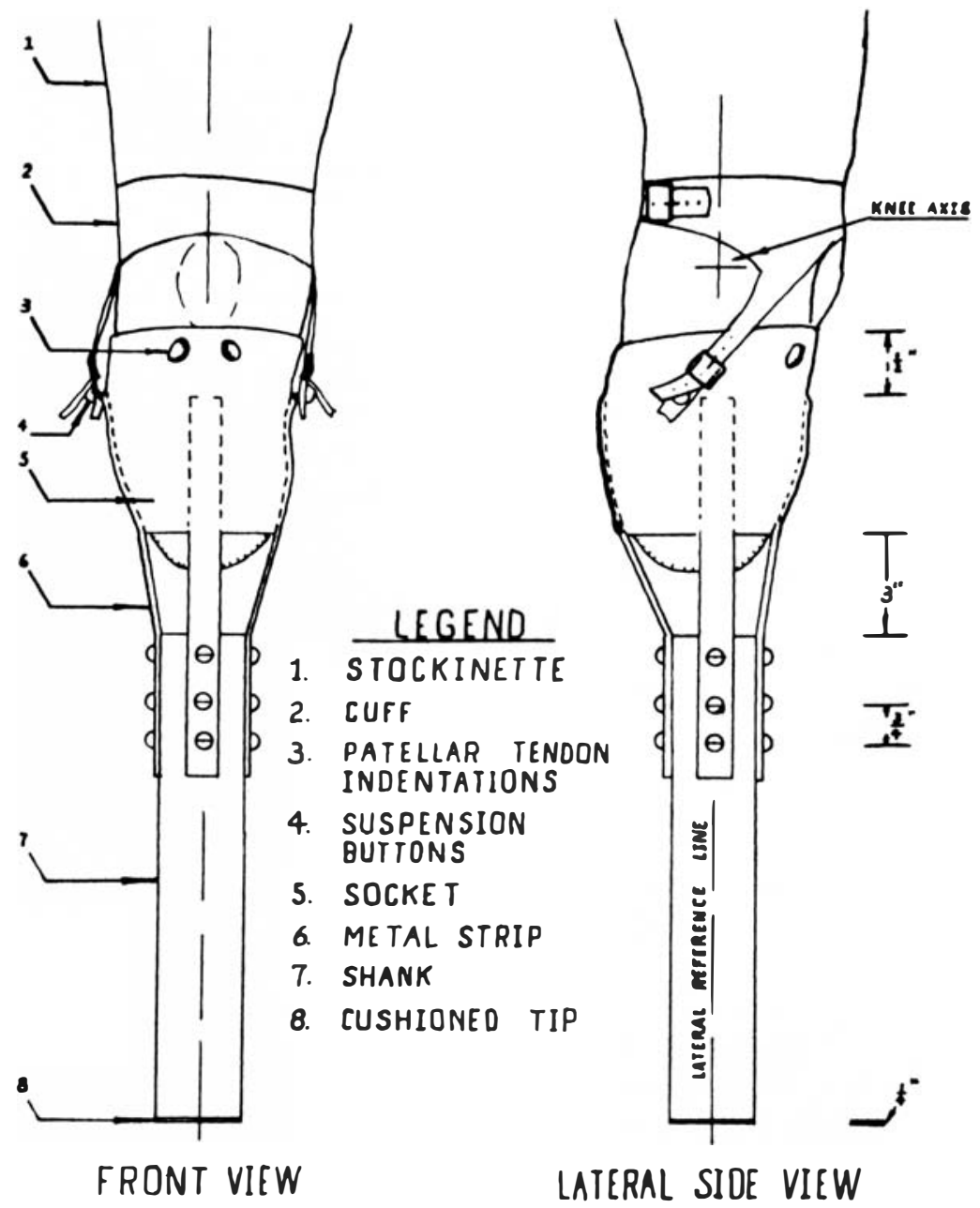

FIG. 2. Below-knee pylon with cuff suspension. 
When the plaster has hardened, lateral and medial vertical reference lines corresponding to the knee axis are marked on the socket as are the anterior and posterior mid lines (Fig. 2). These reference lines aid in determining the position of the metal strips for socket-shank attachment. The socket is then removed from the amputee.

Next, the 4 metal strips $\left(10 \times 1 \times \frac{1}{16}\right.$ inches or $25.4 \times 2.54 \times$ $0.16 \mathrm{~cm})$ are fashioned to the socket's contour. One-half of each metal strip's length is secured to the socket over marked reference lines by circumscribing the socket with $\frac{1}{2}$ of a plaster roll.

After the metal strips are thoroughly secured, 3 holes (corresponding to screw's diameter) are drilled ${ }_{2}^{1}-{ }_{4}^{3}$ inch $(1.27 \mathrm{~cm}$ to $1.91 \mathrm{~cm})$ apart at unsecured end of each metal strip. This will serve for socketshank attachment.

The wood shank $(2 \times 2 \times 18$ inches, or $5.08 \times 5.08 \times 45.72 \mathrm{~cm})$ is placed between the unsecured ends of the 4 metal strips. A distance of 3 inches $(7.62 \mathrm{~cm})$ must separate shank from distal portion of socket to prevent stump tip rubbing against the shank. When the shank has been properly positioned, it is secured to the 4 metal strips by means of screws.

The length of the shank is determined the following day (to allow plaster to set). The amputee is seated in a standard chair with knee of normal leg flexed to 90 degrees and with a shoe on the foot. The distance from the tibial plateau (top rim of socket) to the floor is measured and transferred to the pylon. The extra shank length is sawed off $\frac{1}{4}$ inch $(0.64 \mathrm{~cm})$ shorter than measured distance to permit attachment of rubber tip. The rubber is compressed during the stance phase of walking, thus allowing for shock absorption.

The pylon and stump sock are placed on the stump. The height of the pylon can be checked for error by having the patient seated, both knees flexed to 90 degrees and laying a carpenter's level across the knees. ${ }^{2}$ If an error has been made the cushioned tip can be altered to bring the legs to proper length.

When a below-knee amputee stands, the body's centre of gravity changes from that of a normal subject; as a result, the pylon will often shift laterally when the thrust of body-weight is borne. When this occurs the medial metal strip is repositioned lower on the shank by changing the screw position. This will compensate for the change in the body's centre of gravity.

The cuff is adequate for suspending the pylon to the below-knee amputee. Two small leather straps $\left(1 \frac{1}{2} \times \frac{1}{2}\right.$ inches, or $\left.3.81 \times 1.27 \mathrm{~cm}\right)$ with tabs and buckle are manufactured (Fig. 3). This pattern can be reversed when cuff for left leg is desired. The cuff encircles the knee and rests against upper patellar edge. This serves to lock the patella in position for maintaining pylon in proper position. When bodyweight is borne, the patella rests against the socket indentations 
provided during initial moulding. When the leg is raised in walking, the patella rests against the cuff preventing pylon from falling off. The cuff should be loose upon sitting and snug upon standing.

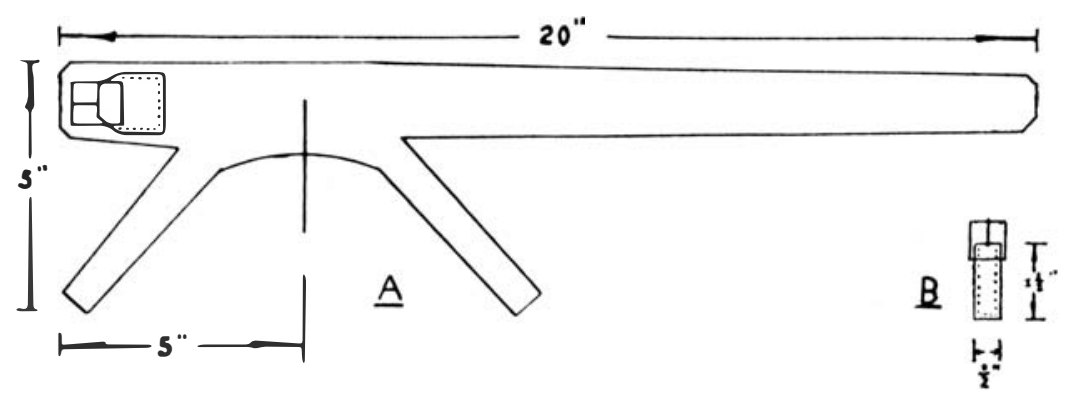

FIG. 3. A-Right knee cuff with tabs. B-Socket strap.

The cuff tabs are adjusted to the socket after the amputee stands on the pylon with body-weight evenly distributed on both legs and cuff is fastened. Pull cuff tabs down on both sides of the knee to their natural position against the socket. Mark the outline of the tabs on the socket. A 1-inch $(2.54 \mathrm{~cm})$ wood screw (suspension button) is inserted directly behind the lateral and medial vertical reference lines (posterior to knee axis) and slightly below top rim of the socket. The screws may be reinforced with small plaster strips. These screws anchor the cuff tabs to the socket.

The pylon is completed and ready to be worn by the amputee for gait training.

\section{Bibliography}

1. Inman, V. T., and Eberhart, H. D., "Manual of Below Knee Prosthetics", U. of California, Berkeley (1959).

2. Hoog, J., "An Experimental Below-The-Knee Prosthesis", The Physical Therapy Review, 38, 326-30 (May 1958). 